\title{
Anthocyanin, Carotenoid, Tocopherol, and Ellagitannin Content of Red Raspberry Cultivars Grown under Field or High Tunnel Cultivation in the Southeastern United States
}

\author{
Christine M. Bradish ${ }^{1}$ \\ Department of Horticultural Science, North Carolina State University, Campus Box 7609, Raleigh, \\ NC 27695 \\ Gad G. Yousef, Guoying Ma, and Penelope Perkins-Veazie \\ Plants for Human Health Institute, Department of Horticultural Science, North Carolina Research \\ Campus, NC State University, 600 Laureate Way, Kannapolis, NC 28081 \\ Gina E. Fernandez \\ Department of Horticultural Science, North Carolina State University, Campus Box 7609, Raleigh, \\ NC 27695
}

\begin{abstract}
AdDitional Index words. Rubus idaeus, phytochemical, bioactive compound, primocane, HPLC
Abstract. High tunnels have been widely adopted for red raspberry (Rubus idaeus) production in the United States to extend the harvest season and increase yields. In this study, effects of high tunnel production on contents of plant secondary metabolites (anthocyanins, carotenoids, tocopherols, and ellagitannins) in red raspberry fruit were determined for three fall-fruiting cultivars (Autumn Britten, Caroline, and Nantahala) grown at three locations in North Carolina under field and high tunnel cultivation systems. Cultivar was the primary contributing factor to variation in phytochemicals, with minor effects of location and production system. The anthocyanin cyanidin-3glucoside and the carotenoids $\alpha$-carotene, $\beta$-carotene, lutein, and zeaxanthin were higher in fruit produced in field compared with tunnel cultivation $(P<\mathbf{0 . 0 1})$. Accumulation of total anthocyanins and tocopherols in fruit were unaffected by high tunnel cultivation in comparison with traditional field cultivation. Carotenoid content varied by genotype and production system. 'Autumn Britten' and 'Caroline' showed no difference, but were higher than 'Nantahala' for $\alpha$-carotene, $\beta$-carotene, 9-cis- $\beta$-carotene, and lutein + zeaxanthin $(P<0.0001)$. Phytochemical differences among field and tunnel produced fruit have important implications for breeding with increased nutritional value in mind, and also the understanding of the relationships of plant pigments to light and temperature.
\end{abstract}

Market demand for fresh red raspberries has greatly increased with health conscious consumers, due to their high flavonoid content (Graham et al., 2009; Seeram, 2008). Red raspberries are eaten fresh, frozen, or processed in a number of food products (Rao and Snyder, 2010; Tokuşoğlu and Stoner, 2011). In addition to vitamins and minerals, the phytochemicals (bioactive compounds) in raspberries have been associated with benefits such as weight management, reduced blood pressure and cholesterol, improved cognitive brain function, slowed agerelated eyesight degeneration, and reduced risk of cardiovascular disease and stroke (Zafra-Stone et al., 2007). Bioactive compounds can function as antioxidants, stopping or limiting damage to cellular DNA, proteins, and lipids caused by reactive oxygen species. A strong association between consumption of antioxidantrich foods and decreased risk of cardiovascular disease and some cancers has been reported (Heinonen et al., 1998).

Received for publication 15 Oct. 2014. Accepted for publication 23 Feb. 2015 We thank the North Carolina Department of Agriculture Specialty Crop Block Grants, Golden Leaf Foundation, Tobacco Trust Fund Commission, and USDANIFA Agriculture and Food Research Initiative Grant no. 2010-65200 for partial funding. We thank Franco Canales, Louis Wojciechowski, Absalom Shank, Joanne Mowery, Larry Wohlers, and Janet Leatherwood, for technical assistance.

${ }^{1}$ Corresponding author. E-mail: cmbradis@ncsu.edu.
Use of high tunnels for fresh market red raspberry production has increased (Darnell et al., 2006; Fernandez et al., 1998; Hanson et al., 2011). High tunnels are large, unheated, hoop-shaped structures covered in greenhouse-grade clear plastic, and offer a level of environmental protection between field and greenhouse production systems (Kadir et al., 2006; Heidenreich et al., 2008). Most high tunnels in the United States and Canada are used for fall-fruiting primocane cultivars to extend the harvest season, increase marketable yields, and improve overall fruit quality (Demchak, 2009; Fernandez and Perkins-Veazie, 2013; Heidenreich et al., 2008). Improved fruit quality can be obtained in high tunnels with fewer pesticide inputs (Demchak, 2009). High tunnel structures shelter fruit from rainfall, keeping the plants and fruit dry and slowing the growth of fungal pathogens, as demonstrated by a $12 \%$ decreased incidence of gray mold (Botrytis cinerea) in tunnel vs. field-grown raspberries in Michigan (Hanson et al., 2011). In North Carolina, red raspberry fruit yields increased $50 \%$ to $80 \%$ in high tunnels, depending on cultivar, due to reduction in gray mold and other diseases (Fernandez and Perkins-Veazie, 2013).

Temperatures in high tunnels remain higher and more stable than in outside conditions, extending the harvest season and protecting high-value crops from winter frost damage 
Table 1. Effect of cultivar and location on total anthocyanins, total phenolics, and ferric reducing antioxidant power (FRAP) of three red raspberry cultivars grown at three locations in North Carolina in 2010 and analyzed by two-way analysis of variance.

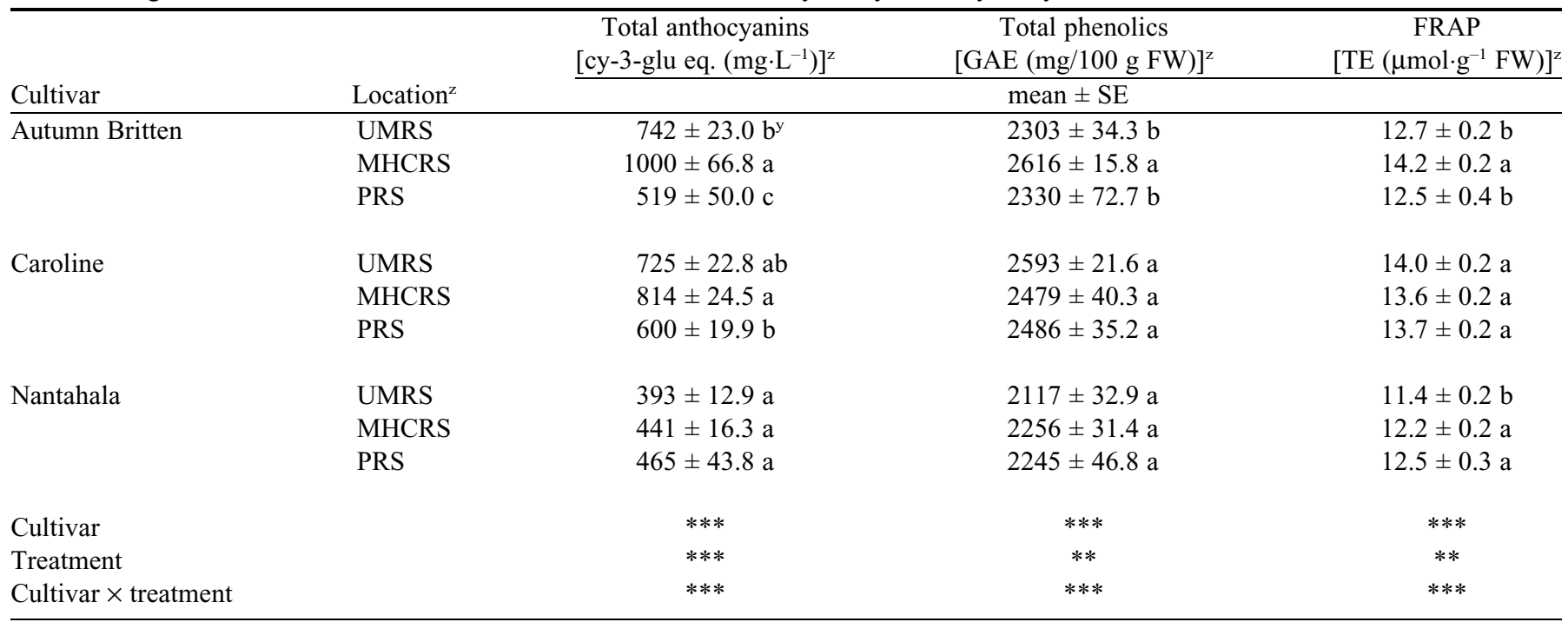

${ }^{\mathrm{z} U M R S}=$ Upper Mountain Research Station (Laurel Springs, NC), MHCRS = Mountain Horticultural Crops Research Station (Mills River, NC), PRS = Piedmont Research Station (Salisbury, NC), cy-3-glu eq. = cyanidin-3-glucoside equivalents, GAE $=$ gallic acid equivalents, TE $=$ trolox equivalents.

${ }^{\mathrm{y}}$ Values are averaged across field and tunnel within location. Different letters within treatment are significantly different at $P<0.05$.

$* * * P<0.0001, * * P<0.01$.

(Carey et al., 2009). Additionally, soil temperatures stay higher in tunnels, allowing for earlier planting dates and harvests. Both floricane and primocane raspberries can have a season extension of 3-4 weeks because of frost-free conditions in the tunnels, extending harvest times by $50 \%$ to $100 \%$ (Heidenreich et al., 2008). Four floricane and four primocane fruiting red raspberry cultivars grown in Michigan yielded $5.5 \mathrm{~kg} \cdot \mathrm{m}^{-1}$ row when grown in tunnels in comparison with $2.5 \mathrm{~kg} \cdot \mathrm{m}^{-1}$ row under field production (Hanson et al., 2011). Primocane fruiting red raspberries grown in tunnels in Pennsylvania had marketable yields of $3.75-5.16 \mathrm{~kg} \cdot \mathrm{m}^{-1}$ row, an increase of $200 \%$ to $300 \%$ compared with field-grown yields in a 5 -year trial, and superior fruit quality and shelf life was obtained without the application of fungicides due to reduced gray mold incidence (Demchak, 2009). Differences in phytochemicals among red raspberry cultivars and locations have been reported in previous research (Anttonen and Karjalainen, 2005; Freeman et al., 2011; Wang et al., 2009), but the effects of high tunnel production on specific bioactive compounds in caneberries (Rubus sp.) is unknown (Thompson et al., 2009).

In this study, three primocane fruiting cultivars of red raspberry grown in replicated yield trials under high tunnel and field cultivation at three locations in central and western North Carolina were evaluated to determine the effects of a warm production climate and high tunnel cultivation on anthocyanin, carotenoid, tocopherol, and ellagitannin content, among a number of other fruit quality factors. Since the effect of high tunnel cultivation on secondary metabolites in red raspberry has not been well established, based on early research in it and on other crops (Hanson et al., 2011; Kassim et al., 2009; Wang et al., 2009), we hypothesized that field and tunnel-grown fruit would differ in quantity and/or type of phytochemicals.

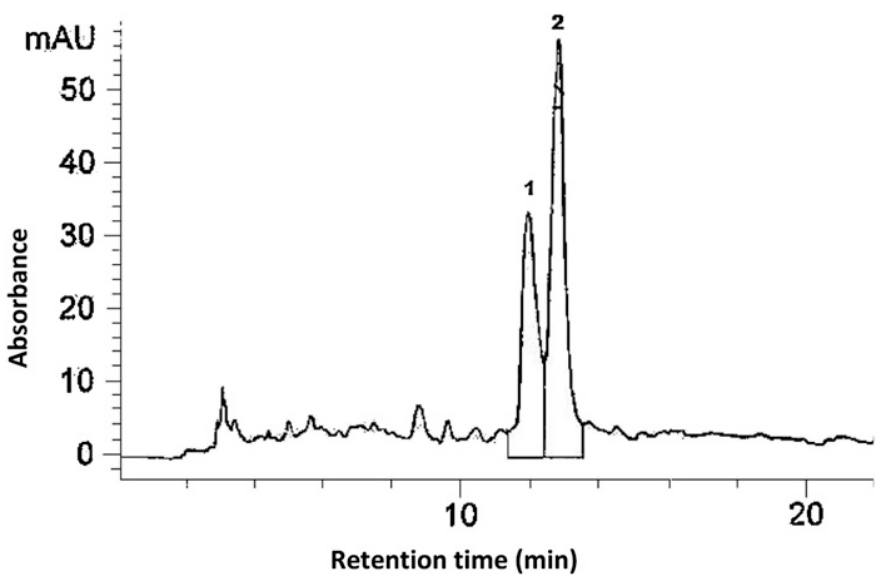

Fig. 1. Chromatographic pattern of 'Autumn Britten' showing major ellagitannins present in red raspberry samples at $280 \mathrm{~nm}$, detected by peak [micro absorbance units $(\mathrm{mAU})]$ and retention time $(\mathrm{min})$, and identified as follows: 1 - lambertianin C (11.8 min); 2 - sanguiin H-6 (12.6 min).

\section{Materials and Methods}

Plant material. Two-year old, primocane-fruiting red raspberry cultivars Autumn Britten, Caroline, and Nantahala were grown in replicated trials at the Piedmont Research Station (PRS), Mountain Horticultural Crops Research Station (MHCRS), and Upper Mountain Research Station (UMRS) located in Salisbury, Mills River, and Laurel Springs, NC, respectively. Elevations are 214, 630, and $917 \mathrm{~m}$ above sea level with average harvest season maximum/minimum temperatures of $30 / 17,27 / 14$, and $23 / 12{ }^{\circ} \mathrm{C}$, respectively. At PRS, primocane fruit harvest in the field was from 1 July to 15 Oct., and in tunnels from 12 June to 19 Oct. At MHCRS primocane 
fruit harvest in the field was from 6 July to 11 Oct., and from 6 July to 25 Oct. in tunnels. For UMRS, primocane fruit harvest in the field was from 19 July to 21 Oct., and 10 July to 1 Nov. in tunnels. Fruit were grown in both open field and quonset-style rounded top high tunnels covered in polyethylene greenhousegrade plastic at each location, in twice-replicated plots, $6.1 \mathrm{~m}$ in length with five plants per plot. Red-ripe fruit of each cultivar were sampled five times from each location between 22 July and 20 Sept. 2010, and then placed into clamshells. Fruit was harvested by plot, with data representing a pooled five-plant average. Samples from the field were stored on ice and transported within $1-4 \mathrm{~h}$ to the laboratory, depending on location, where $50 \mathrm{~g}$ samples were transferred to plastic freezer bags, frozen at $-80{ }^{\circ} \mathrm{C}$ and lyophilized. Each sample was weighed before and after freeze-drying. Average dry weight among all of the samples was used to estimate fresh weight equivalents (grams) for the calculation of phytonutrient contents. Freeze dried fruit were crushed and sieved to remove pyrenes, and fruit tissue of about 40- $\mu \mathrm{m}$ particles was twice extracted in acidified methanol. Sample extracts were centrifuged, filtered, and stored at $-80{ }^{\circ} \mathrm{C}$ in $15-\mathrm{mL}$ brown glass tubes until analysis.

Total anthocyanins. Total anthocyanins of extracts were determined by the $\mathrm{pH}$-differential method of Giusti and Wrolstad (2001) using a spectrophotometer (ultraviolet-2450; Shimadzu Scientific Instruments, Columbia, MD) at absorbance of 510 and $700 \mathrm{~nm}$. Samples were analyzed in triplicate and total anthocyanins reported as milligrams cyanidin-3glucoside (cy-3-glu) equivalents per liter.

Total Phenolics. Total phenolics of extracts were determined by the Folin-Ciocalteu method of Singleton and Rossi (1965). Sample absorbance and gallic acid standards were measured at $765 \mathrm{~nm}$ by spectrophotometer in triplicate. Total phenolics were reported as milligrams gallic acid equivalents (GAE) per $100 \mathrm{~g}$ fresh weight (FW).

Antioxidant CAPACITy. Antioxidant capacity was determined using an adaption of the Ferric Reducing Antioxidant Power (FRAP) method developed by Benzie and Strain (1996). Sample and trolox standard absorbance at $593 \mathrm{~nm}$ was measured in triplicate by spectrophotometer. Antioxidant capacity was reported as micromoles Trolox equivalents (TE) per gram FW.

Measurement of ANTHOCYANINS AND PHENOLIC ACIDS BY HIGH-PERFORMANCE LIQUID CHROMATOGRAPHY. Fruit extracts were filtered through $0.2-\mu \mathrm{m}$ polytetrafluoroethylene (PTFE) membranes (Fisher Scientific, Pittsburgh, PA). Filtered samples were injected into a high-performance liquid chromatography (HPLC) system (1200; Agilent Technologies, Santa Clara, CA) equipped with an ultraviolet-visible diode array detector (ultraviolet-Vis DAD), controlled temperature autosampler $\left(4^{\circ} \mathrm{C}\right)$, and column compartment $\left(30{ }^{\circ} \mathrm{C}\right)$. Chemstation software (Agilent Technologies) was used as the system-run controller and for data processing. Anthocyanin and ellagitannin separation was performed using a reversed-phase $\mathrm{LC}_{18}$ column, $250 \mathrm{~mm} \times 4.6 \mathrm{~mm} \times 5 \mu \mathrm{m}$ (Suplecoil; Supleco, Bellefonte, PA). The mobile phase consisted of 5\% formic acid in water (A) and 100\% methanol (B), with a flow rate of $1 \mathrm{~mL} \cdot \mathrm{min}^{-1}$ using a step gradient of $0 \mathrm{~min}, 10 \% \mathrm{~B} ; 5 \mathrm{~min}, 15 \% \mathrm{~B} ; 15 \mathrm{~min}, 20 \% \mathrm{~B}$; $20 \mathrm{~min}, 25 \% \mathrm{~B} ; 25 \mathrm{~min}, 30 \% \mathrm{~B}$; $45 \mathrm{~min}, 60 \% \mathrm{~B}$; $47 \mathrm{~min}, 10 \% \mathrm{~B}$; $60 \mathrm{~min}, 10 \% \mathrm{~B}$. Compound levels were estimated using standard curves generated by injecting $5 \mu \mathrm{L}$ of $0.0625-0.5 \mathrm{mg} \cdot \mathrm{mL}^{-1}$ preparations for cy-3-glu and ellagic acid (Chromadex, Irvine, CA) as external standards. Quantification of anthocyanins was performed from the peak areas recorded at $520 \mathrm{~nm}$ in reference to the calibration curve of cy-3-glu, and quantification of ellagitannins was performed from the peak areas recorded at $280 \mathrm{~nm}$ in reference to the calibration curve of ellagic acid. Compound identification was performed based on retention time compared with authentic standards, liquid chromatography-mass spectrometry (LCMS) data, and previously published reports (Mullen et al., 2002; Remberg et al., 2010). Each sample was run in duplicate and content reported as milligrams per gram dry weight (DW).

HPLC MEASUREMENT OF CAROTENOIDS AND TOCOPHEROLS. Freeze dried fruit tissue $(0.3-0.5 \mathrm{~g})$ was extracted using hexane:ethanol:acetone at a ratio of $2: 1: 1$ following the

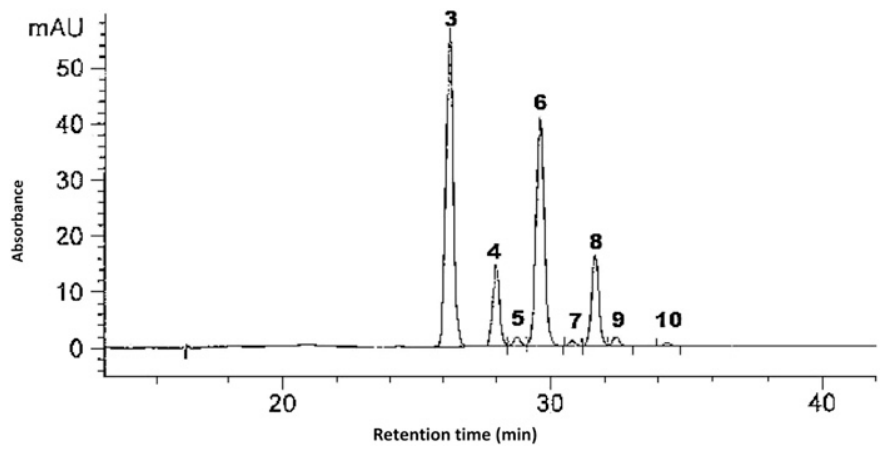

Fig. 2. Chromatographic pattern of 'Caroline' showing anthocyanins present in 'Autumn Britten' and 'Caroline' red raspberry samples at $520 \mathrm{~nm}$, detected by peak [micro absorbance units (mAU)] and retention time $(\mathrm{min})$, and identified as follows: 3 - cyanidin-3-sophoroside (25.9 $\mathrm{min}) ; 4$ - cyanidin-3-2 ${ }^{\mathrm{G}}$-glucosylrutinoside $(27.7 \mathrm{~min}) ; 6$ - cyanidin-3glucoside (29.2 $\mathrm{min}) ; 8$ - cyanidin-3-rutinoside (31.5 $\mathrm{min}) ; 9$ - pelargonidin3 -glucoside $(32.2 \mathrm{~min}) ; 10$ - pelargonidin-3-rutinoside $(34.0 \mathrm{~min})$. In the majority of 'Nantahala' samples, anthocyanins did not peak at point 4,6 , or 8 .

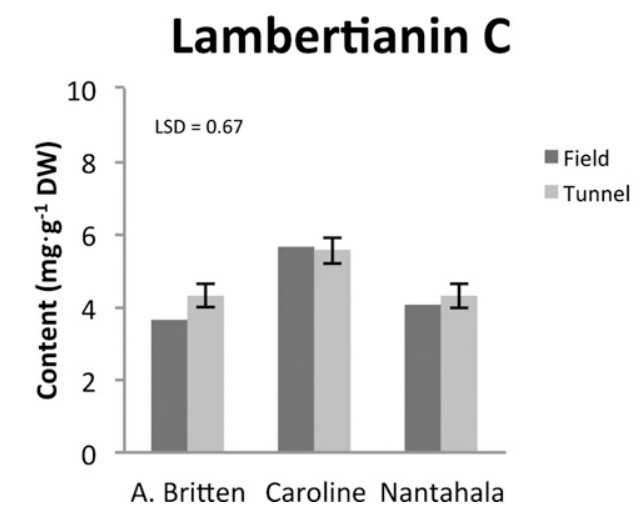

Fig. 3. Ellagitannin content of 'Autumn Britten' (A. Britten), 'Caroline', and 'Nantahala' red raspberry fruit tissue, averaged across location and time. Significance is analyzed by Fisher's least significant difference (LSD), which is indicated graphically for each cultivar. 
Table 2. Effect of cultivar and location on mean levels of major cyanidin anthocyanins [measured as mg. $\mathrm{g}^{-1} \mathrm{dry}$ weight (DW)] of three red raspberry cultivars grown at three locations in North Carolina, 2010 and analyzed by two-way analysis of variance.

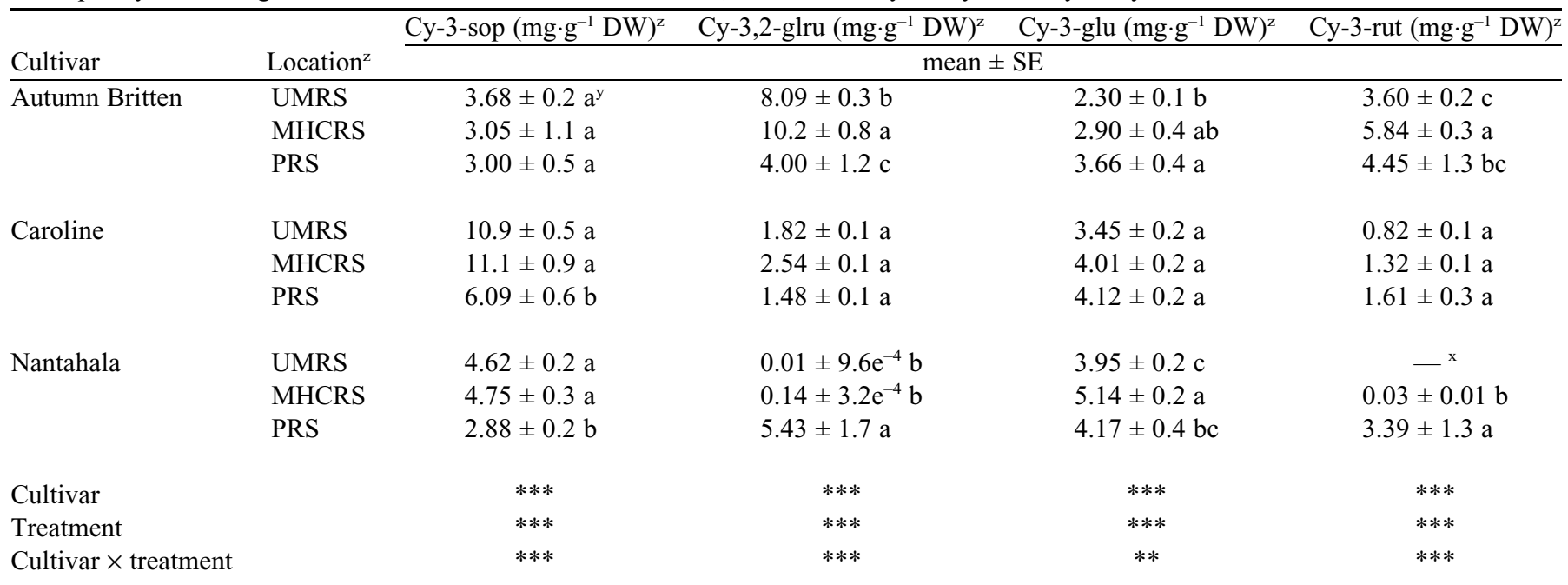

${ }^{{ }^{2} U M R S ~}=$ Upper Mountain Research Station (Laurel Springs, NC), MHCRS = Mountain Horticultural Crops Research Station (Mills River, NC), PRS = Piedmont Research Station (Salisbury, NC), Cy-3-sop = cyanidin-3-sophoroside, Cy-3,2-glru = cyanidin-3-( $2^{\mathrm{G}}$ glucosylrutinoside), Cy-3glu = cyanidin-3-glucoside, Cy-3-rut = cyanidin-3-rutinoside.

${ }^{y}$ Values are averaged across field and tunnel within location. Different letters within treatment are significantly different at $P<0.05$.

${ }^{x} \mathrm{Cy}$-3-rut values for 'Nantahala' at UMRS were not reported because the majority of samples had low compound concentration for accurate detection.

$* * * P<0.0001, * * P<0.01$.

Cyanidin-3-sophoroside

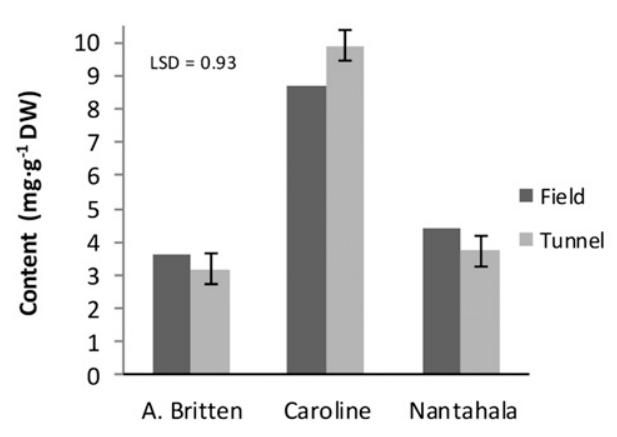

Cyanidin-3-glucoside

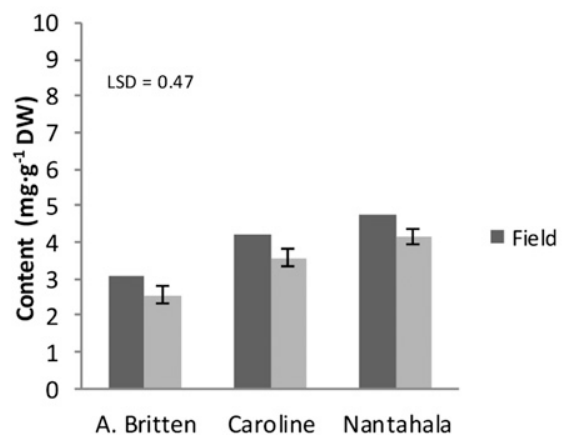

Cyanidin-3-2 ${ }^{\mathrm{G}}$ glucosylrutinoside

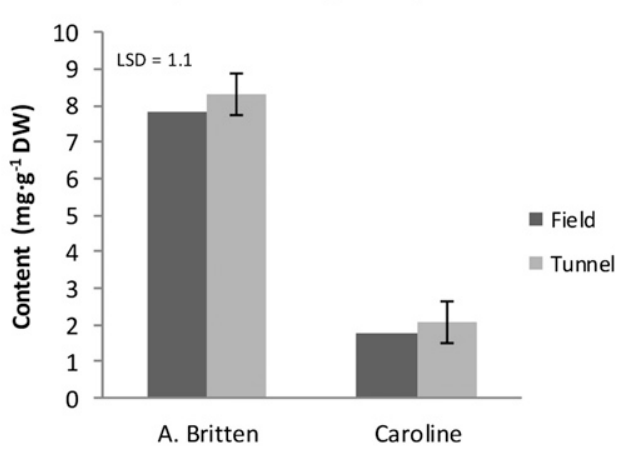

Cyanidin-3-rutinoside

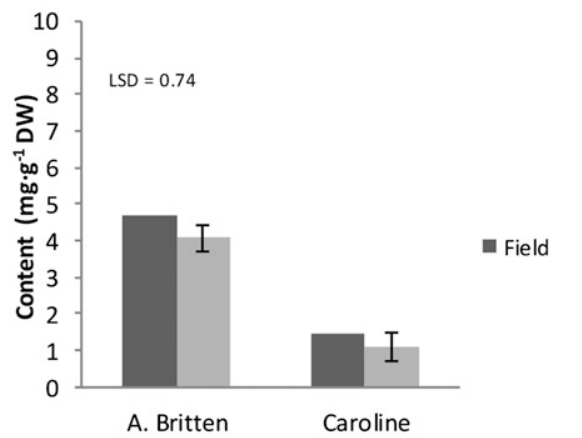

Fig. 4. Anthocyanin content of 'Autumn Britten' (A. Britten), 'Caroline', and 'Nantahala' red raspberry fruit tissue, averaged across location and time. Significance is indicated by Fisher's least significant difference (LSD), shown on each cultivar. In the majority of 'Nantahala' samples, anthocyanins cyanidin-3-2 ${ }^{\mathrm{G}}$-glucosylrutinoside and cyanidin-3-rutinoside were detected at levels too low for quantification.

method of Fish et al. (2002). Each sample was analyzed in triplicate. Six milliliters of the hexane layer was removed and dried under nitrogen gas using an evaporator (N-EVAP III; Organomation Associates, Berlin, MA), and resuspended in

$1 \mathrm{~mL}$ HPLC grade methanol. Extracts $(10-50 \mu \mathrm{L})$ were injected onto a HPLC (Elite; Hitachi High Technologies, Dallas, TX) equipped with a DAD and carotenoid $\mathrm{C}_{30}$ $4.6 \times 250-\mathrm{mm}$ column (YMC America, Allentown, PA). Carotenoids and tocopherols were detected using wavelengths of 470 and $292 \mathrm{~nm}$, respectively. Mobile phase was $0.05 \%$ triethylamine (TEA) with $50 \mathrm{~mm}$ ammonium acetate in methanol (A), $0.05 \%$ TEA in 2-propanol (B), and $0.05 \%$ TEA with $250 \mathrm{mg} \cdot \mathrm{L}^{-1} \mathrm{BHT}$ in THF (C) with a constant flow rate of $1 \mathrm{~mL} \cdot \mathrm{min}^{-1}$ using a step gradient of $0 \min , 90 \% \mathrm{~A}, 10 \% \mathrm{~B}$; $24 \min , 54 \%$ A, $35 \%$ B, $11 \% \mathrm{C} ; 35$ $\min , 30 \% \mathrm{~A}, 35 \% \mathrm{~B}, 35 \% \mathrm{C}$; 43-58 min, $90 \%$ A, $10 \%$ B. Calibration curves were determined using external standards of $\alpha$-carotene, $\beta$-carotene, 9-cis- $\beta$-carotene, lutein, and zeaxanthin (CaroteNature, Ostermundigen, Switzerland) to identify and quantify carotenoids in samples.

Statistical analysis. SAS statistical software (version 9.2; SAS Institute, Cary, NC) was used to perform statistical analyses. The experimental design was a $3 \times 3 \times 2$ factorial ( 3 cultivars, 3 geographic locations, 2 cultural systems). Analysis of variance (ANOVA) and analysis of covariance (ANCOVA) were used to evaluate 


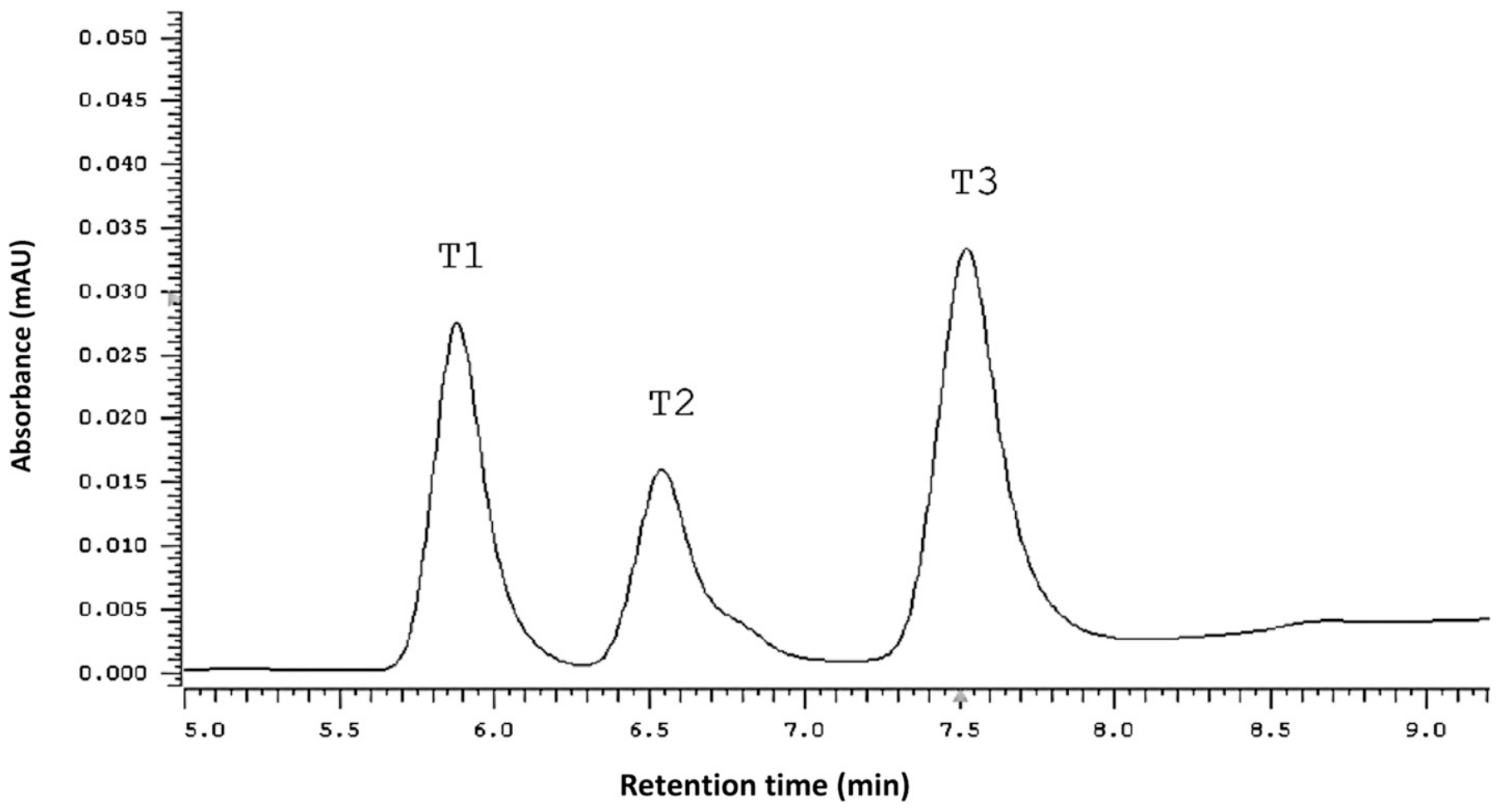

Fig. 5. Chromatographic pattern showing tocopherols present in red raspberry samples at 292nm, detected by peak [micro absorbance units (mAU)] and retention time $(\mathrm{min})$, and identified as follows: T1 $-\delta$-tocopherol $(5.87 \mathrm{~min})$; T2 $-\gamma$-tocopherol $(6.60 \mathrm{~min})$; T3 - $\alpha$-tocopherol $(7.57 \mathrm{~min})$.

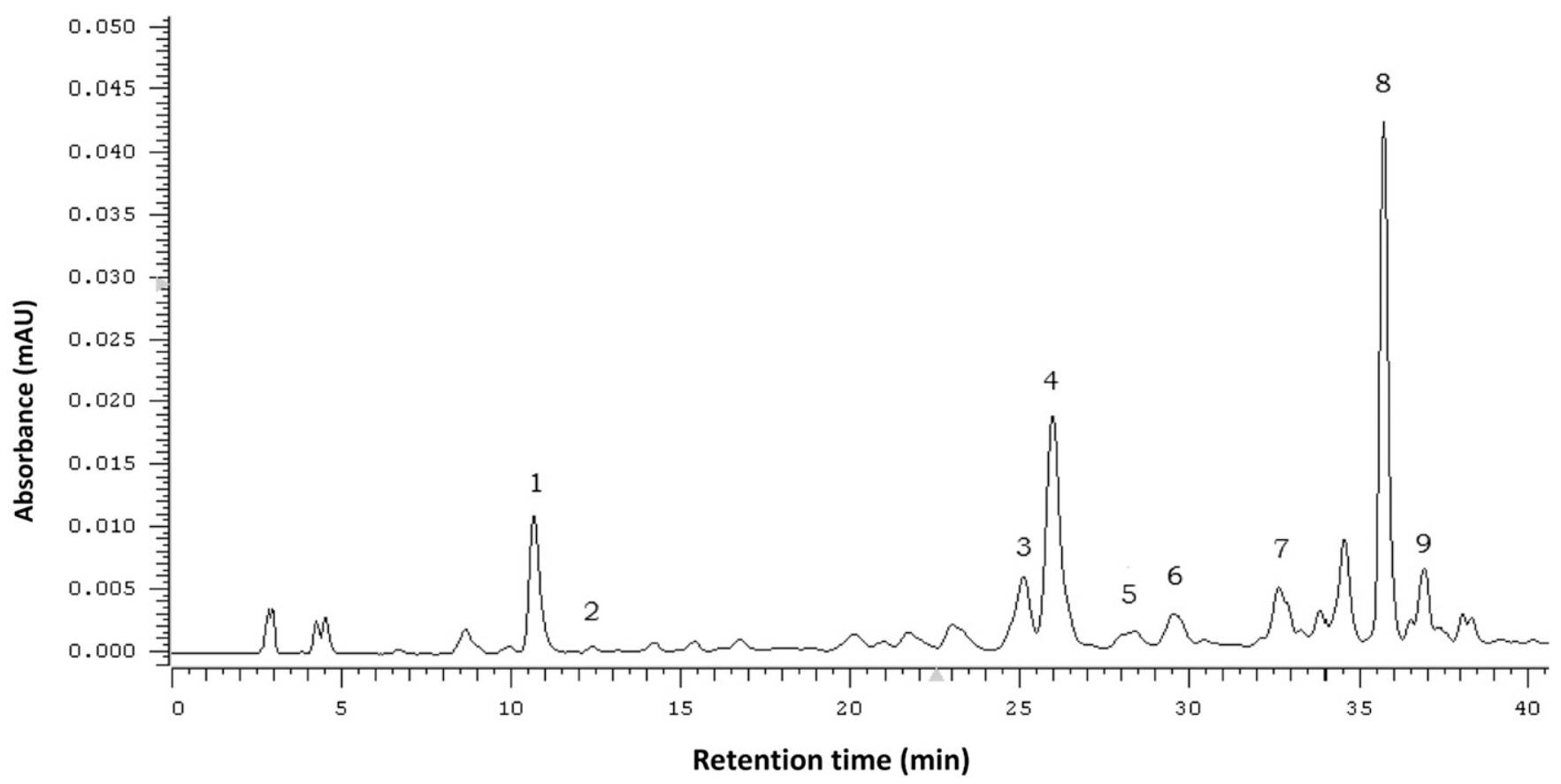

Fig. 6. Chromatographic pattern showing carotenoids and esters present in red raspberry samples at $470 \mathrm{~nm}$ detected by peak [micro absorbance units (mAU)] and retention time $(\mathrm{min})$, and identified as follows: 1 - lutein $(10.9 \mathrm{~min}) ; 2$ - zeaxanthin $(12.2 \mathrm{~min}) ; 3-\alpha$-carotene $(25.0$ min); 4 - carotenoid ester $(25.7 \mathrm{~min}) ; 5$ - $\beta$-carotene $(27.7 \mathrm{~min}) ; 6$ - 9-cis- $\beta$-carotene $(29.2 \mathrm{~min}) ; 7$ - carotenoid ester $(32.8 \mathrm{~min}) ; 8$ - carotenoid ester $(35.7 \mathrm{~min}) ; 9$ - carotenoid ester (36.9 $\mathrm{min})$.

differences in mass abundance of detected compounds, and to determine cultivar, location, time, and temperature effects on the quantity of detected anthocyanins, carotenoids, ellagitannins, tocopherols, and total phenolics, anthocyanins, and antioxidant capacity. LSMEANS with a Bonferroni correction was used to make pairwise comparisons among sample groups (cultivars, locations, cultural systems, harvest dates). Fisher's least significant difference was used to compare mean content among cultivars at $\alpha=0.05$. 


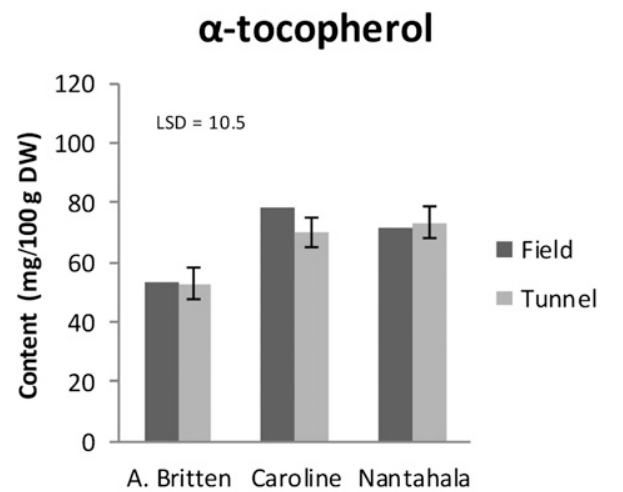

$\gamma$-tocopherol

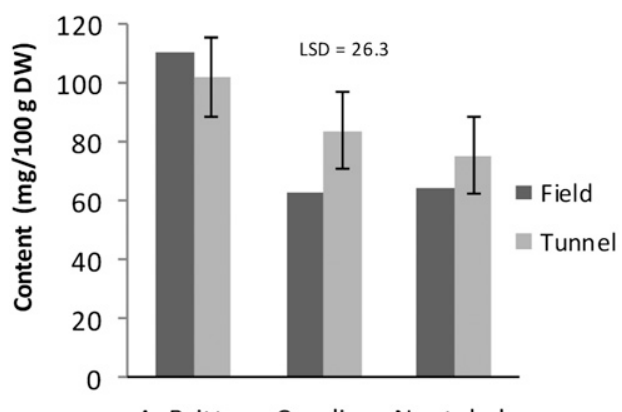

A. Britten Caroline Nantahala

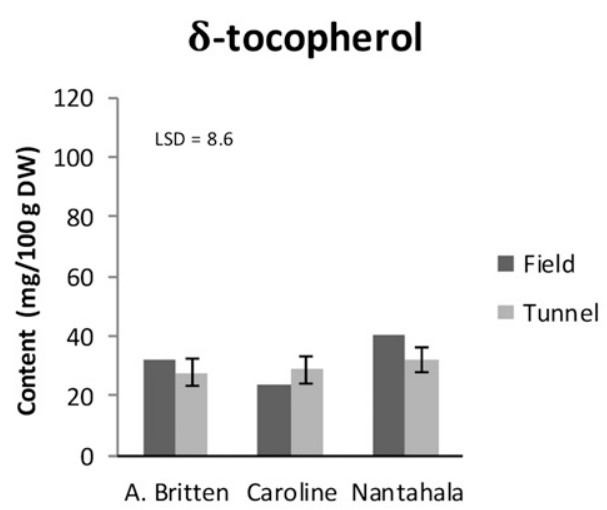

Total Tocopherols

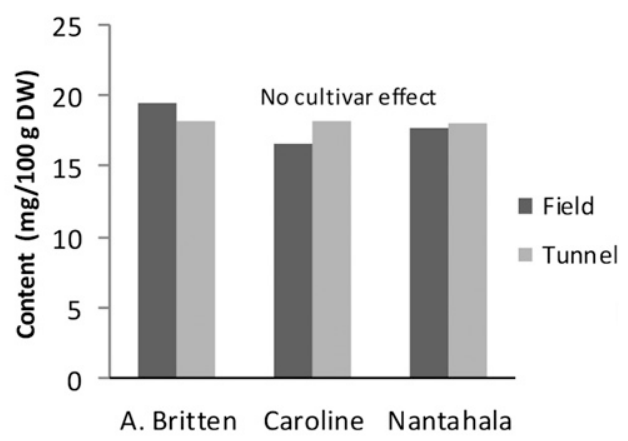

Fig. 7. Tocopherol content of 'Autumn Britten' (A. Britten), 'Caroline', and 'Nantahala' red raspberry fruit tissue, averaged across location and time. Significance is analyzed by Fisher's least significant difference (LSD), indicated graphically for each cultivar.

\section{Results and Discussion}

Total anthocyanins, total phenolics, and antioxidant capacity varied among cultivars $(P<0.0001)$. There were no significant differences between field and tunnel grown fruit, and therefore data were averaged across cultural system (field and tunnel) for each cultivar at each harvest location (Table 1). 'Autumn Britten' and 'Caroline' fruit had higher total anthocyanin values than 'Nantahala' $(P<0.0001)$. Antioxidant capacity and total phenolic content were different among all cultivars, highest for 'Caroline', followed by 'Autumn Britten', and 'Nantahala' $(P<$ 0.01 for all pairwise comparisons).

Cultivar and location interactions were significant for total anthocyanins, total phenolics, and antioxidant capacity (Table 1). 'Autumn Britten' fruit samples from MHCRS had higher $(P<0.001)$ total anthocyanins, phenolics, and antioxidant capacity compared with 'Caroline' and 'Nantahala' fruit from all locations (Table 1). Total anthocyanins measured lower $(P=$ $0.0008)$ in 'Caroline' fruit samples from PRS (600 mg cy-3-glu equivalents per liter) than MHCRS (814 mg cy-3-glu equivalents per liter). 'Autumn Britten' fruit from MHCRS (14.2 $\mu \mathrm{mol}$ TE per gram FW) and 'Caroline' fruit from UMRS $(14.0 \mu \mathrm{mol}$ TE per gram FW) were highest of the three cultivars in antioxidant capacity $(P=0.01)$. Hanson et al. (2011) reported red raspberry genotype $\times$ environment interactions, where 'Caroline' and 'Autumn Britten' fruit from field cultivation were higher in total anthocyanin content and antioxidant capacity than fruit grown in identical plots under high tunnels. In contrast, tunnel-grown 'Heritage' fruit was higher in anthocyanin content and antioxidant capacity than field-grown fruit of the same cultivar.

Growth conditions in high tunnels are thought to mimic field settings except for reduced light exposure and slightly warmer temperatures (Demchak, 2009; Thompson et al., 2009). By convention, high temperatures decrease anthocyanin content, while cool night temperatures contribute to anthocyanin accumulation and pigmentation in fruit species through effects on biosynthetic pathway enzymes and activity in the cell nucleus (Ozgen et al., 2008; Steyn, 2009). In contrast to this, a study by Remberg et al. (2010) on 'Glen Ample' raspberries under controlled environment found that as postflowering temperature increased from 12 to $24{ }^{\circ} \mathrm{C}$, total phenolics, total anthocyanins, and antioxidant capacity significantly increased. Studies in Michigan by Hanson et al. (2011) found differences in field and tunnel grown fruit depended on cultivar. Our results do not show differences in cultural system; however, differences were reported among locations in North Carolina dependent on cultivar. For each of these studies, more variation in anthocyanins, phenolics, and antioxidant capacity can be attributed to individual genotype of raspberries vs. environment, however environment could be defined in terms of temperature-range, whether among growth chambers, cultural system, or geographic location.

Ellagitannins, a major class of hydrolizable tannins, were measured in all samples (Fig. 1). Peak 1 in Figure 1 was identified as lambertianin $C$, and peak 2 as sanguiin H-6 through chromatogram comparison from previous reports (Mullen et al., 2002; Remberg et al., 2010) and LC-MS confirmation. Significant differences among cultivars were found (Fig. 3), with major ellagitannins highest in 'Caroline' (13.8 $\mathrm{mg} \cdot \mathrm{g}^{-1}$ DW, $\left.P<0.0001\right)$. Ellagitannin content did not differ significantly between tunnel and field-cultivated samples. Stephens et al. (2012) found ellagitannins in red raspberry to have moderate narrow-sense heritability estimates $\left(\mathrm{h}^{2}=0.46\right)$, and genotype $\times$ year correlations $\left(\mathrm{r}_{\mathrm{GY}}=0.67\right)$, indicating that ellagitannin levels are primarily under genetic control. There was a cultivar $\times$ location interaction for Sanguiin H-6 content $(P=0.0094)$. 'Caroline' fruit from UMRS $\left(9.31 \mathrm{mg} \cdot \mathrm{g}^{-1} \mathrm{DW}\right)$ contained higher Sanguiin H-6 than fruit grown at PRS (7.67 $\mathrm{mg} \cdot \mathrm{g}^{-1} \mathrm{DW}$ ), while the other cultivars showed no response with location. This response of 'Caroline' fruit, or lack of response in 'Autumn Britten' and 'Nantahala' fruit, could be due to genetic differences among cultivars for ellagitannin content, combined with sensitivity of specific cultivars to soil conditions, lower night temperatures, and less exposure to heat stress conditions (temperatures over $29^{\circ} \mathrm{C}$ ) at UMRS (Molina-Bravo et al., 2011; CRONOS Weather System, Raleigh, NC). 

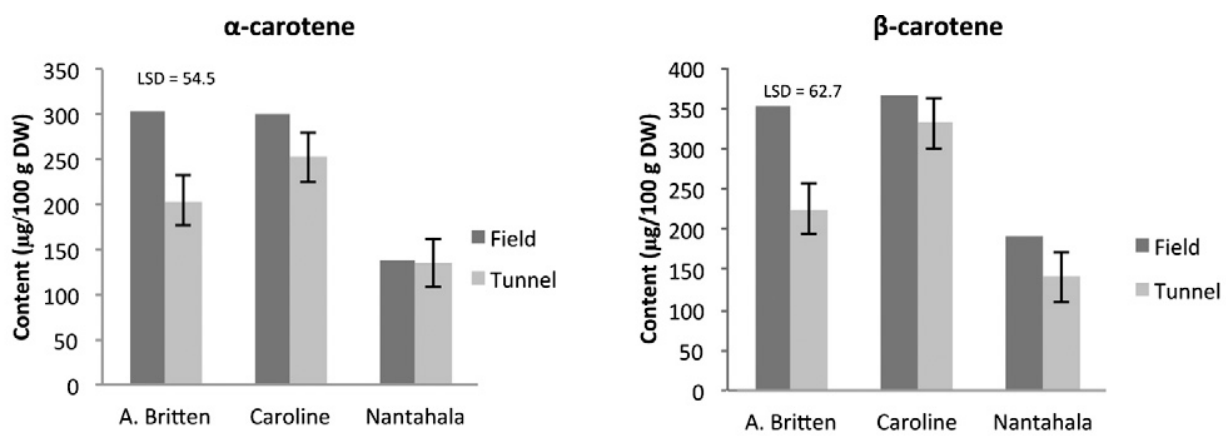

Lutein+Zeaxanthin

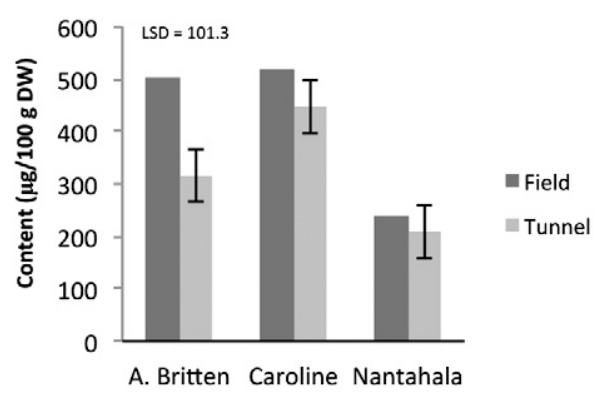

Total Carotenoids
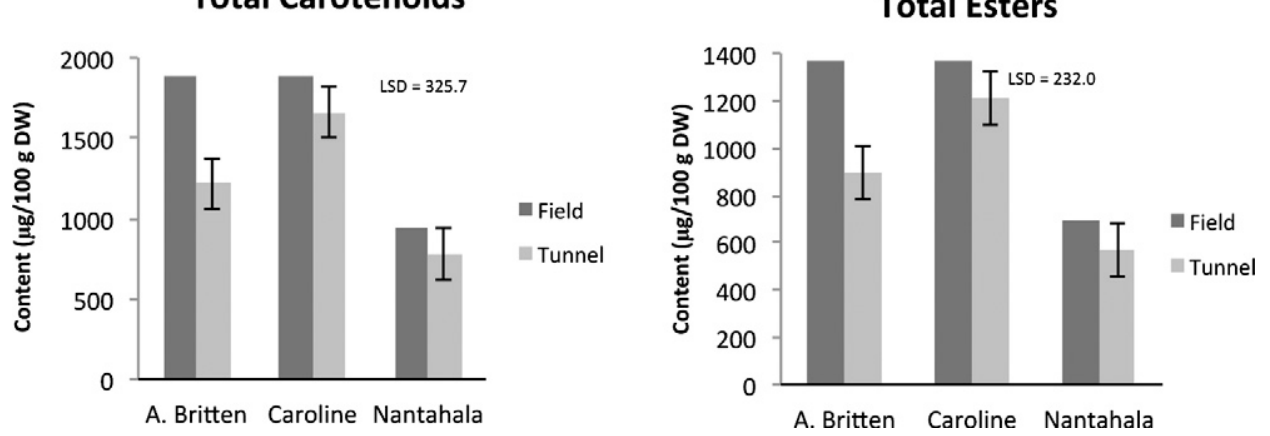

Fig. 8. Carotenoid and ester content of 'Autumn Britten' (A. Britten), 'Caroline', and 'Nantahala' red raspberry fruit tissue, averaged across location and time. Significance is analyzed by Fisher's least significant difference (LSD), indicated graphically for each cultivar.

Anthocyanin peaks in Figure 2 were identified as cyanidin3 -sophoroside [cy-3-sop (peak 3)], cyanidin-3-( $\left(2^{\mathrm{G}}\right.$ glucosylrutinoside) [cy-3,2-glru (peak 4)], cy-3-glu [peak 6; which is also known to elute with cyanidin-3-sambubioside (cy-3-sam)], and cyanidin-3-rutinoside [cy-3-rut (peak 8)] based on previous reports and the use of external standards (Bradish et al., 2012; Mullen et al., 2002). Based on elution patterns and known low levels within red raspberry fruit, peaks 9 and 10 were identified as pelargonidin-3-glucoside and pelargonidin-3-rutinoside (pel-3-glu and pel-3-rut, respectively). Peaks 5 and 7 could not be positively identified. Cy-3-glu and cy-3-sop were the most abundant in all of the samples and are generally characterized as the two primary anthocyanins in red raspberry (Anttonen and Karjalainen, 2005).

Previous studies indicate that anthocyanin accumulation in red raspberry is primarily under genetic control, with some variation due to environmental factors (Anttonen and Karjalainen, 2005; Conner et al., 2005; Freeman et al., 2011; Kassim et al., 2009; Ozgen et al., 2008; Stephens et al., 2012). Consistent with these reports, the majority of differences in anthocyanin content or individual anthocyanins were found among cultivars in our study. Although few differences were found in total anthocyanin content among harvest locations or production systems, interactions of cultivar and location and cultivar and cultural system were found among individual anthocyanins. When averaged over cultural system and time, cy-3-sop in 'Caroline' was highest, while 'Autumn Britten' and 'Nantahala' were not different (Table 2, Fig. 5). Cy-3,2-glru and cy-3-rut were highest in 'Autumn Britten', while 'Caroline' and 'Nantahala' were not different. Cy-3-glu was highest in 'Nantahala' compared with the two other cultivars. However, cy-3-glu content was confounded because of its coelution with cy-3-sam. Cy-3-sam is typically found in black ( $R$. occidentalis) and purple (R. neglectus) raspberries (Dossett et al., 2008; Jennings, 1988; Tulio et al., 2008). 'Nantahala' is one-quarter purple raspberry, and measures higher in cy-3-sam in comparison with 'Autumn Britten' and 'Caroline' red raspberries (Bradish et al., 2012).

The interaction of cultivar $\times$ location was not uniform. Cy-3-sop and cyanidin-3,2-glru were lower in fruit from PRS $(P<0.01)$ than in those from UMRS or MHCRS (Table 2). Cy-3-rut content was highest at MHCRS, followed by PRS, and lowest at UMRS (Table 2). Cultivar and location interactions were observed in cy-3-sop, cy-3,2-glru, and cy-3rut. For cy-3-sop, the interaction of location and cultivar was more profound in 'Caroline' and 'Nantahala' berries, while interactions for cy-3,2-glru and cy-3-rut were more distinct in 'Autumn Britten' fruit (Table 2).

Cy-3-glu was the only anthocyanin in all the red raspberry cultivars that consistently differed between field and tunnel samples $[P=0.0028$ (Fig. 4)]. Overall cy-3-glu was higher in fruit grown in field $\left(4.01 \mathrm{mg} \cdot \mathrm{g}^{-1} \mathrm{DW}\right)$ vs. tunnel cultivation (3.42 $\mathrm{mg} \cdot \mathrm{g}^{-1} \mathrm{DW}$ ), when samples were pooled over location and time or cultivar, location, and time. This result is consistent with results from Kassim et al. (2009) and Bradish et al. (2012). Decreased cy-3-glu and total skin anthocyanins were correlated to shading and high air temperatures in 'Merlot' grape (Vitis vinifera) in a study by Tarara et al. (2008), similar to the high tunnel conditions with red raspberry fruit in our study.

In contrast to results with cy-3-glu, the interaction of cultivar $x$ cultural system shows that cy-3-rut was higher in fruit grown under field vs. tunnel cultivation, (Fig. 4) and this effect was highly cultivar dependent. In particular, 'Autumn Britten' and 'Nantahala' fruit from field grown plants had more cyanidin-3rutinoside (4.67 and $4.07 \mathrm{mg} \cdot \mathrm{g}^{-1} \mathrm{DW}$, respectively) than 'Caroline' fruit from either field or tunnel or tunnel culture 
[1.43 and $1.09 \mathrm{mg} \cdot \mathrm{g}^{-1} \mathrm{DW}$, respectively $\left.(P<0.0001)\right]$. Cy-3-rut and cy-3,2-glru for 'Nantahala' grown under high tunnels could not be quantified due to low compound concentration for accurate detection in the majority of samples. While cultivar or genotype effects generally control the content of flavonoid profiles, our results suggest that genotype $\times$ environment interactions may affect the quantity of specific flavonoids.

No genotype, location, or cultural system effects were found for pel-3-glu and pel-3-rut. This concurs with the results of Kassim et al. (2009) where pelargonidin content in red raspberry was unaffected by cultural system, suggesting that pel-3-glu and pel-3-rut levels in red raspberry fruit are controlled independently of environment.

Carotenoids and tocopherols contribute light quenching ability in plants, and $\alpha$ - and $\beta$-carotenoids offer foundation for the norisoprenoids $\alpha$ - and $\beta$-ionones that provide flavor in red raspberry fruit (Beekwilder et al., 2008). Three tocopherols (Figs. 5 and 7) and five carotenoids (Figs. 6 and 8) were identified in 'Autumn Britten', 'Caroline', and 'Nantahala': $\delta$-tocopherol, $\gamma$-tocopherol, $\alpha$-tocopherol, lutein, zeaxanthin, $\alpha$-carotene, $\beta$-carotene, and 9 -cis- $\beta$-carotene. As quantities of zeaxanthin were very low, lutein + zeaxanthin were combined for statistical analysis.

Cultivar was the primary source of variance for carotenoids analyzed, along with some production system differences. Harvest date and location had no significant impact on variance, therefore samples were averaged over location and time. 'Autumn Britten' and 'Caroline' fruit were higher than 'Nantahala' for $\alpha$-carotene, $\beta$-carotene, 9-cis- $\beta$-carotene, and lutein + zeaxanthin $(P<0.0001)$. Within cultivars, field-grown raspberries had higher $\alpha$-carotene, $\beta$-carotene, lutein + zeaxanthin and total carotenoids than fruit from high tunnels. Lutein and carotenoid esters followed a similar pattern for cultivar and cultural systems. 'Caroline' fruit had the highest amount of total esters (217 $\mu \mathrm{g} / 100 \mathrm{~g} \mathrm{DW})$, and field fruit was higher than tunnel fruit for 'Autumn Britten' and 'Caroline' (Fig. 8). Carotenoid esters in red raspberry appear to be from lutein (Carvalho et al., 2013). The higher carotenoid content found in field-grown raspberries compared with tunnel grown fruit indicates higher ultraviolet-light exposure in the field and the accumulation of carotenoids with known protective photochemical-quenching properties (Hirschberg, 2001).

The tocopherols alpha, gamma, and delta were quantified in red raspberry fruit tissue and differed with both cultivar and production location $(P<0.01)$, but not cultural system. Alphatocopherol was highest in 'Caroline' $(12.5 \mathrm{mg} / 100 \mathrm{~g} \mathrm{DW})$ and 'Nantahala' ( $12.1 \mathrm{mg} / 100 \mathrm{~g} \mathrm{DW})$ fruit, while $\delta$-tocopherol was higher in 'Autumn Britten' (17.6 mg/100 g DW) than in 'Nantahala' fruit (11.7 mg/100 g DW). Raspberries from UMRS were highest in $\delta$-tocopherol and total tocopherols. Our samples, which were from fruit tissue only, had less $\gamma$ - and more $\alpha$ - and $\delta$-tocopherol, in contrast to Carvalho et al. (2013), where $\alpha$-tocopherol was least in samples that incorporated both fruit and pyrene tissue. The large differences in tocopherol content among red raspberry cultivars were also noted by Carvalho et al. (2013).

With interest in breeding for nutritional value and the growing use of high tunnels, it is important to understand how high tunnel production affects phytochemical accumulation. In this study, we determined the flavonoid and carotenoid composition of red raspberries grown in field and high tunnel cultivation in a warm temperate climate in the southern United
States. In general, we found that the effects of high tunnel production and location on plant secondary metabolites measured were small compared with the influence of cultivar. High tunnel cultivation had minor effects on total anthocyanin or tocopherol content of red raspberry, while carotenoid content was higher in fruit grown in the field than in tunnel cultivation. The anthocyanins are more concentrated than the carotenoid pigments in red raspberry fruit, indicating that carotenoid pigments play an ancillary role for photoprotection or as precursors of aroma volatiles. Genotypes had the most profound differences among phytochemical levels. Production system had less pronounced effects on total contents, but did affect individual compounds. Our results support the hypothesis that red raspberry germplasm offers a primary source of variance in anthocyanin and carotenoids of fruit, while environmental effects such as those from elevation or protected culture have a secondary role.

\section{Literature Cited}

Anttonen, M.J. and R.O. Karjalainen. 2005. Environmental and genetic variation of phenolic compounds in red raspberry. J. Food Compos. Anal. 18:759-769.

Beekwilder, J., I. van der Meer, A. Simic, J. Uitdewilligen, J. van Arkel, R. de Vos, H. Jonker, F. Verstappen, H. Bouwmeester, O. Sibbesen, I. Qvist, J. Mikkelsen, and R. Hall. 2008. Metabolism of carotenoids and apocarotenoids during ripening of raspberry fruit. Biofactors 34:57-66.

Benzie, I.F.F. and J.J. Strain. 1996. The ferric reducing ability of plasma (FRAP) as a measure of "antioxidant power": The FRAP assay. Ann. Biochem. 239:70-76.

Bradish, C., P. Perkins-veazie, G. Fernandez, G. Xie, and W. Jia. 2012. Comparison of flavonoid composition of red raspberries (Rubus idaeus L.) grown in the southern U.S. J. Agr. Food Chem. 60:5779-5786.

Carey, E., L. Jett, W. Lamont, Jr., T. Nennich, M. Orzolek, and K. Williams. 2009. Horticultural crop production in high tunnels in the United States: A snapshot. HortTechnology 19:37-43.

Carvalho, E., P. Fraser, and S. Martens. 2013. Carotenoids and tocopherols in yellow and red raspberries. Food Chem. 139:744-752.

Conner, A., T. McGhie, M. Stephens, H. Hall, and P. Alspach. 2005. Variation and heritability estimates of anthocyanins and their relationship to antioxidant activity in a red raspberry factorial mating design. J. Amer. Soc. Hort. Sci. 130:534-542.

Darnell, R., B. Brunner, H. Alavarado, J. Williamson, M. Plaza, and E. Negron. 2006. Annual, off-season raspberry production in warm season climates. HortTechnology 16:92-97.

Demchak, K. 2009. Small fruit production in high tunnels. HortTechnology 19:44-49.

Dossett, M., J. Lee, and C.E. Finn. 2008. Inheritance of phenological, vegetative, and fruit chemistry traits in black raspberry. J. Amer. Soc. Hort. Sci. 133:408-417.

Fernandez, G., F. Louws, J.R. Ballington, and E.B. Poling. 1998. Growing raspberries in North Carolina. North Carolina Coop. Ext. Serv. Publ. AG-569.

Fernandez, G.E. and P. Perkins-Veazie. 2013. Yield and postharvest attributes of caneberries grown under high tunnels and in the open field in North Carolina. Acta Hort. 987:89-98.

Fish, W., P. Perkins-Veazie, and J.K. Collins. 2002. A quantitative assay for lycopene that utilizes reduced volumes of organic solvents. J. Food Compos. Anal. 15:309-317.

Freeman, B., J.C. Stocks, D.L. Eggett, and T.L. Parker. 2011. Antioxidant and phenolic changes across one harvest season and two storage conditions in primocane raspberries (Rubus idaeus L.) grown in a hot, dry climate. HortScience 46:236-239.

Giusti, M. and R. Wrolstad. 2001. Characterization and measurement of anthocyanins by UV-visible spectroscopy. Current Protocols Food Anal. Chem. F1.2.1-13. 
Graham, J., C.A. Hackett, K. Smith, M. Woodhead, I. Hein, and S. McCallum. 2009. Mapping QTLs for developmental traits in raspberry from bud break to ripe fruit. Theor. Appl. Genet. 118:1143-1155.

Hanson, E., M. Von Weihe, A. Schilder, A. Chanon, and J. Scheerens. 2011. High tunnel and open field production of floricane and primocane-fruiting raspberry cultivars. HortTechnology 21:412-418.

Heidenreich, C., M. Pritts, M.J. Kelly, and K. Demchak. 2008. High tunnel raspberries and blackberries. Cornell Univ. Dept. Hort. Publ. No. 47.

Heinonen, I., A. Meyer, and E. Frankel. 1998. Antioxidant activity of berry phenolics on human low-density lipoprotein and liposome oxidation. J. Agr. Food Chem. 46:4107-4112.

Hirschberg, J. 2001. Carotenoid biosynthesis in flowering plants. Curr. Opin. Plant Biol. 4:210-218.

Jennings, D.L. 1988. Raspberries and blackberries: Their breeding, diseases, and growth. Academic Press, San Diego, CA.

Kadir, S., E. Carey, and S. Ennahli. 2006. Influence of high tunnel and field conditions on strawberry growth and development. HortScience 41:329-335.

Kassim, A., J. Poette, A. Paterson, D. Zait, S. McCallum, M. Woodhead, K. Smith, C. Hackett, and J. Graham. 2009. Environmental and seasonal influences on red raspberry anthocyanin antioxidant contents and identification of quantitative traits loci (QTL). Mol. Nutr. Food Res. 53:625-634.

Molina-Bravo, R., C. Arellano, B. Sosinski, and G. Fernandez. 2011. A protocol to assess heat tolerance in a segregating population of raspberry using chlorophyll fluorescence. Sci. Hort. 130:524-530.

Mullen, W., J. McGinn, M. Lean, M. MacLean, P. Gardner, G. Duthie, T. Yokota, and A. Crozier. 2002. Ellagitannins, flavonoids, and other phenolics in red raspberry and their contribution to antioxidant capacity and vasorelaxtion properties. J. Agr. Food Chem. 50:5191-5196.

Ozgen, M., F. Wyzgoski, A. Tulio, Jr., A. Gazula, A. Miller, J. Scheerens, R. Reese, and S. Wright. 2008. Antioxidant capacity and phenolic antioxidants of midwestern black raspberries grown for direct markets are influenced by production site. HortScience 43:2039-2047.
Remberg, S., A. Sønsteby, K. Aaby, and O. Heide. 2010. Influence of postflowering temperature on fruit size and chemical composition of Glen Ample raspberry (Rubus idaeus L.). J. Agr. Food Chem. 58:9120-9128.

Rao, A. and D. Snyder. 2010. Raspberries and human health: A review. J. Agr. Food Chem. 58:3871-3883.

Seeram, N. 2008. Berry fruits: Compositional elements, biochemical activities, and the impact of their intake on human health, performance, and disease. J. Agr. Food Chem. 56:627-629.

Singleton, V. and J. Rossi. 1965. Colorimetry of total phenolics with phosphomolybdic-phosphotungstic reagents. Amer. J. Enol. Viticult. 16:144-158.

Stephens, M., P. Alspach, R. Beatson, C. Winefield, and E. Buck. 2012. Genetic parameters and development of a selection index for breeding red raspberries for processing. J. Amer. Soc. Hort. Sci. 137:236-242.

Steyn, W. 2009. Prevalence and functions of anthocyanins in fruits, p. 85-105. In: K. Gould, K. Davies, and C. Winefield (eds.). Anthocyanins. Springer Science+Business Media, New York, NY.

Tarara, J., J. Lee, S. Spayd, and C. Scagel. 2008. Berry temperature and solar radiation alter acylation, proportion, and concentration of anthocyanin in merlot grapes. Amer. J. Enol. Viticult. 59:235-247.

Thompson, E., B. Strik, C. Finn, Y. Zhao, and J. Clark. 2009. High tunnel versus open field: Management of primocane-fruiting blackberry using pruning and tipping to increase yield and extend the fruiting season. HortScience 44:1581-1587.

Tokuşoğlu, Ö. and G. Stoner. 2011. Phytochemical bioactives in berries, p. 143-162. In: O. Tokuşoğlu and C. Moore (eds.). Fruit and cereal bioactives. CRC Press, Boca Raton, FL.

Tulio, A., Jr., R. Reese, F. Wyzgoski, P.L. Rinaldi, R. Fu, J.C. Scheerens, and A. Miller. 2008. Cyanidin-3-rutinoside and cyanidin-3-xylosylrutinoside as primary phenolic antioxidants in black raspberry. J. Agr. Food Chem. 56:1880-1888.

Wang, S.Y., C. Chen, and C.Y. Wang. 2009. The influence of light and maturity on fruit quality and flavonoid content of red raspberries. Food Chem. 112:676-684.

Zafra-Stone, S., T. Yasmin, M. Bagchi, A. Chatterjee, J. Vinson, and D. Bagchi. 2007. Berry anthocyanins as novel antioxidants in human health and disease prevention. Mol. Nutr. Food Res. 51:675-683. 